\title{
PDXI, a key factor in pancreatic embryogenesis, can exhibit antimetastatic activity in pancreatic ductal adenocarcinoma
}

This article was published in the following Dove Press journal: Cancer Management and Research

\author{
Liya G Kondratyeval,* \\ Dina R Safina ${ }^{2, *}$ \\ Igor P Chernov' \\ Eugene P Kopantzev' \\ Sergey $V$ Kostrov ${ }^{2}$ \\ Eugene D Sverdlov ${ }^{1,2}$ \\ 'Shemyakin-Ovchinnikov Institute of \\ Bioorganic Chemistry of the Russian \\ Academy of Sciences, Moscow, Russia; \\ ${ }^{2}$ Institute of Molecular Genetics Russian \\ Academy of Sciences, Moscow, Russia \\ *These authors contributed equally to \\ this work
}

Background: In cancer biology, metastasizing is one of the most poorly studied processes. Pancreatic ductal adenocarcinoma (PDAC) is characterized by early metastasis, which is the leading cause of death. The PDX1 protein is crucial for the development of cancer, and its low levels are characteristic of the most aggressive PDAC tumors. The PDX1 is a mediator of initiation and progression of PDAC. However, further studies are needed to elucidate the role of PDX1 in the cancer metastasis.

Purpose: To confirm the hypothesis that PDX1 in PDAC plays suppressor role of epithelialmesenchymal transition (EMT), and to study its possible ability to inhibit metastasis.

Methods: A PDX1-overexpressing PDAC cell line was obtained by lentiviral transduction of PANC-1 cells. PDX1 overexpression was confirmed by RT-PCR and Western blotting. Effects of PDX1 ectopic expression on cell proliferation and motility were determined in PANC-1 cells using MTS, cell cycle analysis, transwell and wound-healing assay. EMT genes expression was analyzed in PDX1-overexpressing and Control PANC-1. Finally, the migration potential of pancreatic cancer cells expressing PDX1 was evaluated using a zebrafish embryo model.

Results: The motility of human PDAC cells PANC-1 considerably decreased at ectopic expression of PDX1. The decreased expression of ZEB1, the key factor of EMT, and almost unchanged expression of the genes that characterize the epithelial state suggest a decrease in the EMT ability. Suppression of PDX1 expression by siRNA knockdown restored the PANC1 motility.

Conclusion: The results obtained suggest a possible therapeutic use of PDX1 delivery into PDAC patients with a reduced or absent expression of PDX1 in the most aggressive tumors. Keywords: metastasis, PDAC, PDX1, epithelial-mesenchymal transition, Danio rerio

\section{Introduction}

Pancreatic ductal adenocarcinoma (PDAC) is on the way from the fourth to the second top position in global cancer mortality by 2030. The frequency of emergence and mortality of PDAC is almost the same due to the combination of usually late diagnostics, aggressive clinical course, and poor reaction to chemo- and radiotherapy. ${ }^{1}$ Early resection of primary tumor without detectable metastases prevents further growth of tumor and increases the survival rate. Unfortunately, even radical surgery does not prevent the development of metastases from previously disseminated cancer cells. ${ }^{2}$ The genetic heterogeneity of PDAC and different oncogenic susceptibility of different compartments within the pancreas make this disease opposite to what clinicians call "a chameleon," that is one disease with many faces. Instead, PDAC may represent numerous diseases with the same
Correspondence: Eugene D Sverdlov Shemyakin-Ovchinnikov Institute of Bioorganic Chemistry of the Russian Academy of Sciences, 2 Kurchatov Square, Moscow 123182, Russia

$\mathrm{Tel}+74953306529$

Fax +7 4953350812

Email edsverd@gmail.com 
appearance. ${ }^{3}$ In addition to the genetic heterogeneity, the results of some studies indicate possible multifocal neoplasia in the pancreas. ${ }^{4,5}$

In PDAC, as well as in other malignant tumors, metastasis is the main cause of death of cancer patients and often occurs at early stages of cancer development. In cancer biology, metastasizing is one of the most poorly studied phenomena. ${ }^{6,7}$ It is a complex process; the majority of cancers have specific features of metastasis, so that the exact ways of dissemination of cancer cells from their primary sites, their migration, and subsequent invasion into distant parts of the organism remain unknown. In addition, it is currently evident that metastasizing is not an autonomous program of cancer cells, but a complex chain of events affected by intracellular mutations, multiple interactions between malignant and stromal cells, and signals of the extracellular matrix. Steps of successful metastasis include angiogenesis/lymphangiogenesis, epithelial-mesenchymal transition (EMT), invasion to surrounding tissues and migration, formation of a premetastatic niche, and growth at the metastatic site, ${ }^{6}$ with its own regulatory factors involved. Previous reviews ${ }^{6,8-10}$ mention also the role of the richness of genomic aberrations and a strong link between cancer stem cells and metastatic events in PDAC. ${ }^{9}$ Recently, microRNAs and exosomes have also been suggested to play a regulatory role in the metastatic behavior of many tumors, including PDAC. ${ }^{9}$ The development of metastases may be correlated to a more mesenchymal transcriptomic subtype. ${ }^{10}$

Another key determinant in cancer development and metastasis is the tumor microenvironment (for a recent review, see $\left.{ }^{11}\right)$. In particular, cancer-associated fibroblasts (CAFs) are often found in the vicinity of or in direct contact with neoplastic cells and can co-travel in the blood with circulating murine metastatic lung carcinoma cancer cells, probably supporting the cancer cell viability and growth advantage at the metastatic site. It is quite possible that other factors implicated in the formation of PDAC metastasis remain largely unknown and undefined. ${ }^{9}$

It is usually accepted that metastasis is linked to the EMT of cancer cells ${ }^{12}$, although recently it was called in question. ${ }^{13,14}$ It was supposed that there are EMT-dependent and EMT-independent mechanisms of metastasis, although the mechanisms of these processes remain unclear and are possibly different for different types of cancer. In its turn, the process of EMT depends on a complex network of cytokines, transcription factors, growth factors, signaling pathways, and the tumor microenvironment. The transition of cancer cells to a mesenchymal state increases their migratory and invasive properties, increasing metastasis probability.

Over the last two decades, therapy of malignant tumors has made considerable progress due to a breakthrough in cancer immunotherapy. However, therapy of PDAC cancer developed slowly, and the success of immunotherapy did not have any effect on it. Generally, PDAC remains "A Riddle Wrapped in a Mystery inside an Enigma." 15 Therefore, the problem of PDAC therapy is extremely urgent. Recently, the attention of researchers was attracted by PDX1, the key regulator of the pancreas development. Yu et $\mathrm{al}^{16}$ developed different methods of inhibiting Pdx 1 expression, which led to a prolonged survival in mouse PDAC models. The authors argued that strategies directed at the PDX1 therapy might allow to cure PDAC. ${ }^{16}$ However, these data were criticized by another group of researchers, ${ }^{12}$ who showed that PDX1 was a context-dependent mediator of initiation and progression of PDAC. According to their data, the definition of PDX1 as a fully pro- or anticancer factor is false, and it would be premature to treat it as a therapeutic target without further understanding of its various functions, as proposed by a previous study. ${ }^{16}$ The PDX1 protein is crucial for cancer development, but blocking it may lead to more aggressive tumors. Further studies are needed to examine how PDX1 interacts with various co-regulators and modulates critical aspects of cancer development. $^{12}$

In the present study, using Danio rerio (zebrafish) as a model organism, we report that the motility of human PDAC cells PANC-1 considerably decreased at ectopic expression of a key factor of pancreas embryogenesis PDX1. The decreased expression of $Z E B 1$, the key factor of epithelialmesenchymal transition (EMT), and almost unchanged expression of the genes that characterize the epithelial state suggest a decrease in the EMT ability. Suppression of $P D X 1$ expression by siRNA restores the motility. On the assumption that EMT is a prerequisite of metastasis, the decreased motility may indicate a decline in metastatic potential. These results suggest a possibility of gene therapeutic use of $P D X 1$ delivery into PDAC cells with the reduced or absent expression of $P D X 1$, which are known to be the most aggressive.

\section{Materials and methods}

\section{Cell cultures}

PANC-1 (ATCC ${ }^{\circledR}$ CRL-1469) and 293T (ATCC ${ }^{\circledR}$ CRL$3216^{\mathrm{TM}}$ ) cells were obtained from the American Type Culture Collection (ATCC, Manassas, VA, USA). The cells were cultured in DMEM supplemented with 10,000 
$\mathrm{U} / \mathrm{mL}$ penicillin, $10 \mathrm{mg} / \mathrm{mL}$ streptomycin, and $10 \%$ FBS Media and supplements were purchased from Gibco (Carlsbad, CA, USA). Cells were maintained in a humidified atmosphere containing $5 \% \mathrm{CO}_{2}$ at $37^{\circ} \mathrm{C}$.

\section{Lentivirus vector design and production}

Three lentivirus vectors were designed to express green fluorescent protein (GFP) under the control of the CMV promoter, to express the PDX1 gene under control of the PCNA promoter and the puromycin-resistance gene under control of the PGK promoter, and to express solely the puromycin-resistance gene under the control of the PGK promoter. To express GFP under the control of the CMV promoter, lentiviral expression vector pLVT (kindly provided by Prof. V.V. Belousov, Institute of Bioorganic Chemistry, Russian Academy of Sciences, Moscow) was created as previously described. ${ }^{17}$ The promoter of the human PCNA gene ${ }^{18}$ was amplified from a fragment of human genomic DNA at -241 to +148 from the transcription start site. The PCNA promoter was amplified by PCR with the primers PCNA-LS 5'-TCTCCACATATGCC CGGACT-3' and PCNA-R 5'-GCAACAACGCCGCTA CAG-3'. The amplification products were cloned into a pAL-TA vector (Evrogen, Moscow, Russia) and then subcloned into a pLVPGm.1 vector. The PDX1 (Pancreatic and duodenal homeobox 1) human gene was derived from a pCMV6 plasmid (OriGene Technologies, Rockville, $\mathrm{MD}$, USA, cat. no. RC222354) and inserted under the control of the PCNA promoter. ${ }^{18,19}$ The negative control vector contained only a puromycin-resistance cassette. Following DNA sequencing confirmation, the successfully constructed vectors containing $P D X 1$ and control were transfected with Lipofectamine ${ }^{\circledR} 2000$ (Invitrogen Life Technologies,Carlsbad, CA, USA) into $80 \%$ confluent $293 \mathrm{~T}$ cells for $48 \mathrm{hrs}$ at $37^{\circ} \mathrm{C}$. The cell culture medium containing the lentivirus was collected and stored at $-70^{\circ} \mathrm{C}$.

\section{Lentiviral transduction of cancer cells}

PANC-1 cells were transduced with lentiviral particles containing the PCNA promoter to express $P D X 1$ and those containing the control vector. Transduction was performed in 6-well plates seeded with $3 \times 10^{5}$ PANC- 1 cells/well followed by puromycin selection $(4 \mu \mathrm{g} / \mathrm{mL})$ for 10 days. The cell lines stably expressing $P D X 1$ and control cells were maintained in puromycin $(2 \mu \mathrm{g} / \mathrm{mL})$. The generated stable cell lines were named PANC-1 ${ }^{P D X 1}$ and PANC-1 ${ }^{\text {Control }}$, respectively.
Next, PANC-1 ${ }^{P D X 1}$ and PANC-1 ${ }^{\text {Control }}$ cells were transduced with lentiviral particles containing Turbo-GFP under the control of the CMV promoter. The transduction was performed as described previously. GFP-positive (GFP+) transduced cells were selected using a fluorescence-activated cell sorter FACSAria III (BD Bioscience, San Jose, CA, USA).

\section{Quantitative polymerase chain reaction ( $\mathrm{QPCR}$ )}

Total RNA was extracted using Extract RNA reagent (Evrogen) and reverse-transcribed into cDNA using Mint Reverse Transcriptase (Evrogen). qPCR was performed to determine the gene expression levels in the PANC-1 ${ }^{P D X 1}$ and PANC-1 Control cells on a LightCycler480 Real-Time PCR platform (Roche Applied Science, Mannheim, Germany). qPCRmix-HSSYBR was used to determine the relative RNA expression. Primer sequences are shown in Table 1. The 18SRNA and EEFla genes were used as an internal control. The PCR reaction conditions were as follows: 1 cycle at $90^{\circ} \mathrm{C}$ for 5 mins; 40 cycles at $95^{\circ} \mathrm{C}$ for $20 \mathrm{~s}, 60^{\circ} \mathrm{C}$ for $20 \mathrm{~s}$. and $72^{\circ} \mathrm{C}$ for $35 \mathrm{sec}$; and 1 cycle at $95^{\circ} \mathrm{C}$ for $5 \mathrm{~s}$, $55^{\circ} \mathrm{C}$ for $60 \mathrm{~s}$, and $97^{\circ} \mathrm{C}$ for $15 \mathrm{sec}$. The experiments were performed in triplicate for each sample. A relative expression ratio of $P D X 1$ was normalized by using geometric means of the 18SRNA and EEFla expression levels. Calculations were performed according to Ganger et $\mathrm{al}^{20}$ for the relative expression ratio.

\section{Western blotting}

The lentivirus-transduced cells were lysed in SDS sample buffer containing $1 \%$ SDS, 2\% 2-mercaptoethanol, and 62 $\mathrm{mM}$ Tris- $\mathrm{HCl}, \mathrm{pH} 6.8$, subjected to SDS electrophoresis on $10-15 \%$ polyacrylamide gels and then electrotransferred to a Polyvinylidene difluoride (PVDF) Immobilon- $P$ membrane (Millipore, Burlington, MA, USA) using a Bio-Rad TransBlot SD cell (Bio-Rad Laboratories, Hercules, CA, USA). The membranes were blocked with 5\% skimmed milk in PBS-T (PBS containing 0.1\% Tween 20) for $1 \mathrm{hr}$ at room temperature, incubated in PBS-T containing 5\% skimmed milk and the relevant primary antibody overnight at $4{ }^{\circ} \mathrm{C}$, and finally washed three times with PBS-T. The membranes were then incubated with indicated primary antibodies rabbit anti-PDX1 (1:1000; Cat. no. 5679; Cell Signaling Technology, Danvers, MA, USA) and mouse anti-GAPDH (1:60,000; Cat. no. 10494-1-AP; Santa Cruz Biotechnology Inc., Dallas, TX, USA) at $4^{\circ} \mathrm{C}$ overnight, followed by incubation with horseradish peroxidase (HRP)-conjugated secondary antibodies (1:5000; Cat. no. sc-2054; Santa Cruz 
Table I Real-time PCR primers used in gene expression analysis

\begin{tabular}{|c|c|c|c|}
\hline \multirow{2}{*}{$\frac{\text { Gene }}{185}$} & \multicolumn{2}{|c|}{ Primer sequence $\left(5^{\prime} \rightarrow 3^{\prime}\right)$} & \multirow{2}{*}{$\frac{\text { PCR product (bp) }}{501}$} \\
\hline & $\begin{array}{l}\mathrm{Fw} \\
\mathrm{Rv}\end{array}$ & $\begin{array}{l}\text { CGCGGTTCTATTTTGTTGGT } \\
\text { ATGCCAGAGTCTCGTTCGTT }\end{array}$ & \\
\hline EEFIa & $\begin{array}{l}\mathrm{Fw} \\
\mathrm{Rv}\end{array}$ & $\begin{array}{l}\text { GACACGTAGATTCGGGCAAG } \\
\text { GATACCACGTTCACGCTCA }\end{array}$ & 173 \\
\hline PDXI & $\begin{array}{l}\mathrm{Fw} \\
\mathrm{Rv}\end{array}$ & $\begin{array}{l}\text { GTCCTGGAGGAGCCCAAC } \\
\text { CGGCGGTTTTGGAACCAGAT }\end{array}$ & 272 \\
\hline $\mathrm{CDHI}$ & $\begin{array}{l}\mathrm{Fw} \\
\mathrm{Rv}\end{array}$ & $\begin{array}{l}\text { AGTGCCTGCTTTTGATGATG } \\
\text { AGCTTGAACTGCCGAAAAATC }\end{array}$ & 338 \\
\hline KRT8 & $\begin{array}{l}\mathrm{Fw} \\
\mathrm{Rv}\end{array}$ & $\begin{array}{l}\text { ATGTTGTCCATGTTGCTTCG } \\
\text { ACCCTCAACAAGTTTGCC }\end{array}$ & 125 \\
\hline MUCI & $\begin{array}{l}\mathrm{Fw} \\
\mathrm{Rv}\end{array}$ & $\begin{array}{l}\text { CTGGTCTGTGTTCTGGTTGC } \\
\text { CCACTGCTGGGTTTGTGTAAG }\end{array}$ & 250 \\
\hline KLF5 & $\begin{array}{l}\text { Fw } \\
\text { Rv }\end{array}$ & $\begin{array}{l}\text { ACAAATCAGACAGCAGCAATGGACA } \\
\text { GGTGGTGGGTAAATTTGGATTGTGA }\end{array}$ & 312 \\
\hline VIM & $\begin{array}{l}\mathrm{Fw} \\
\mathrm{Rv}\end{array}$ & $\begin{array}{l}\text { GCAGAAGAATGGTACAAATCCA } \\
\text { TTTAAGGGCATCCACTTCACA }\end{array}$ & 144 \\
\hline SNAIL & $\begin{array}{l}\mathrm{Fw} \\
\mathrm{Rv}\end{array}$ & $\begin{array}{l}\text { CCAATCGGAAGCCTAACTAC } \\
\text { GCGGTGGGGTTGAGGATCTC }\end{array}$ & 124 \\
\hline SLUG & $\begin{array}{l}\mathrm{Fw} \\
\mathrm{Rv}\end{array}$ & $\begin{array}{l}\text { AGAAGGTTTTGGAAGCAGTTTTTTG } \\
\text { TGGTTGCTTCAAGGACACAT }\end{array}$ & 160 \\
\hline ZEBI & $\begin{array}{l}\text { Fw } \\
\text { Rv }\end{array}$ & $\begin{array}{l}\text { GAACAGTGTTCCATGCTTAAGAGCG } \\
\text { GGGCGGTGTAGAATCAGAGTCATTC }\end{array}$ & 217 \\
\hline
\end{tabular}

Abbreviations: Fw, forward primer; Rw, reverse primer; bp, base pair.

Biotechnology Inc.) at room temperature for $1 \mathrm{hr}$. Mouse monoclonal anti-GAPDH antibody was used as a loading control. After washing, the membranes were incubated in PBS-T containing 5\% skimmed milk and goat anti-mouse or anti-rabbit antibody HRP conjugates (Santa Cruz, 1:5.000) for $1 \mathrm{hr}$ at room temperature. The membranes were finally washed with PBS-T, and specific signals were visualized using a Clarity Western ECL (Bio-Rad Laboratories) with a VersaDoc Imaging System (Bio-Rad Laboratories).

\section{RNA interference}

A siRNA sequence targeting human PDXI (Si-135: 5'GCCACGCAGCTTTACAAG-3', Si-464: 5'-TCCCATGG ATGAAGTCTAC-3', Si-599 5'-AGTTCCTATTCAACAA GTA-3') was designed and synthesized (Syntol, Moscow, Russia). Silencer ${ }^{\mathrm{TM}}$ Negative Control No. 1 siRNA (Ambion, Waltham, MA, USA, Cat \#AM4635) was used as a negative control for siRNA.
Transfections were carried out using the Lipofectamine RNAiMAX reagent (Invitrogen), following the manufacturer's instructions. To achieve the best depletion of PDX1, transfection was conducted twice: $24 \mathrm{hrs}$ after seeding the cells and $48 \mathrm{hrs}$ after the first transfection. siRNA-treated cells were injected into zebrafish embryos $24 \mathrm{hrs}$ after the second transfection.

\section{Cell proliferation assay}

Cell proliferaion assay was performed using CellTiter $96^{\circledR}$ AQueous One Solution Cell Proliferation Assay (MTS) (Promega, Madison, WI, USA). Following the lentivirus transduction, the PANC-1 ${ }^{P D X I}$ and PANC-1 ${ }^{\text {Control }}$ (2000 cells/well) cells were seeded each into 96-well plates. MTS solution (5 $\mathrm{mg} / \mathrm{mL} ; 20 \mu \mathrm{L}$ ) was added into each well. The MTS solution was aspirated off following incubation for $1 \mathrm{hr}$ at $37^{\circ} \mathrm{C}$. The absorbance of each plate was measured at $595 \mathrm{~nm}$ using a Benchmark Plus microplate reader (Bio-Rad Laboratories). 


\section{Cell cycle analysis}

Cells were collected in the logarithmic phase, plated onto 6 -well plates at $1 \times 10^{5}$ cells per well, and incubated for 24 hrs. After that, the cells were digested with $0.25 \%$ trypsin, centrifuged at $1000 \mathrm{rpm}$ for $5 \mathrm{mins}$, and then the supernatant was discarded. Remainders were washed with PBS twice. One milliliter of $70 \%$ ethanol was added, and after that the samples were held at $4^{\circ} \mathrm{C}$ for $24 \mathrm{hrs}$. Later, the samples were washed and centrifuged again. Staining buffer, propidium iodide (PI) staining solution $(20 \times)$, and RNase A (50×) were added to the samples, which were then incubated for 30 mins at room temperature under darkroom conditions. PI fluorescence was detected using a Cytomics FC500 (Beckman Coulter, Bray, CA, USA) flow cytometry system and analyzed using a MultiCycle (Beckman Coulter).

\section{Migration - cell wound closure assay}

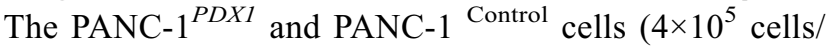
well) were plated onto 6-well plates for $24 \mathrm{hrs}$ to a confluence of about $80 \%$, then wounded by scratching with a p200 pipette tip. The debris was removed, and the cells were washed once with $1 \mathrm{~mL}$ of growth medium to assure that the edges of the scratch were smoothed by washing. We took utmost care to make wounds of the same dimension, both for the experimental and control cells, to minimize any possible variety resulting from a difference in the scratch width. GFPlabeled PANC-1 ${ }^{P D X 1}$ and PANC-1 ${ }^{\text {Control }}$ cell migration was assessed by a monolayer gap closure migration assay, using the free ImageJ software (version 1.50i, National Institute of Health, Bethesda, MD, USA). The area of the initial wound was measured, followed by gap area measurements after 12 and $24 \mathrm{hrs}$.

\section{Transwell assay}

The migration assay was performed on transwell plates. For cell migration assay, $2 \times 10^{5}$ cells were seeded on a polycarbonate membrane transwell inserts containing 8 $\mu \mathrm{m}$ pores (Corning, Corning, NY, USA) and cultured in DMEM without serum. DMEM containing 10\% FBS was added to the lower chamber. After incubation for $24 \mathrm{hrs}$ at $37^{\circ} \mathrm{C}$ in a $\mathrm{CO}_{2}$ incubator, the insert was washed with $\mathrm{PBS}$, and cells on the top surface of the insert were removed using a cotton swab. GFP-labeled PANC-1 ${ }^{P D X I}$ and PANC- $1^{\text {Control }}$ cells that migrated to the bottom surface of the insert were counted in five random fields.

\section{Statistical analysis}

Data were expressed as the mean (SD) or SEM. The significance of differences for the data obtained was estimated using the Wilcoxon-Mann-Whitney $U$ test and the STATISTICA software package (Stat-Soft, Dell Software Company, Round Rock, TX, USA).

\section{Zebrafish husbandry}

Experiments on animals were conducted in strict accordance with the ethics principles prescribed by the European Convention for the Protection of Vertebrates and the bioethics norms (https://rm.coe.int/168007a67b).

The fish were kept in a flow-through aquarium system (Aqua Schwarz GmbH, Göttingen, Germany) at $28^{\circ} \mathrm{C}$. The light conditions corresponding to the international standards were maintained in a light/dark proportion of $14 \mathrm{hrs} / 10 \mathrm{hrs}$. The fish were fed once a day with Artemia salina nauplia (Barrom, Barnaul, Russia) and dry Sera Vipan food (Sera $\mathrm{GmbH}$, Heinsberg, Germany). The wild-type Danio rerio $\mathrm{AB}$ line was used in the work.

\section{Preparation of cancer cells for xenotransplantation}

To prepare cell samples, cells were treated with $0.25 \%$ trypsin in a Hanks solution (PanEco, Moscow, Russia) and washed with a PBS solution (PanEco) to obtain cellular suspension at the concentration of $10^{6}$ cells per 100 $\mu \mathrm{L}$ of PBS.

\section{Xenotransplantation of cancer cells into Danio rerio embryo}

To perform xenotransplantation, embryos at the age of 48 hpf (hours post fertilization), previously dechorionized and anesthetized with a $0.006 \%$ tricaine solution (SigmaAldrich, St. Louis, MO, USA), were used.

The embryos were placed onto an agarose support, and cells were injected into the yolk sac using a PicoPump PV820 pneumatic microinjector (World Precision Instruments, Inc., Sarasota, FL, USA) with the pressure parameters set at $20 \mathrm{psi}$ and the sample submission time of $100 \mathrm{~ms}$; an M-152 micromanipulator (Narashige Group, Tokyo, Japan); and an Olympus CKX41 microscope (Olympus, Japan). Glass capillaries (cat.\# BF100-50-10 Sutter Instrument, Novato, CA, USA), with the outer diameter of $40 \mu \mathrm{m}$, produced by a Model P-97 device (Sutter Instrument), were employed. 
The postinjection embryos were held in water at $+28^{\circ} \mathrm{C}$ for $2 \mathrm{hrs}$, and the temperature was raised to $+34{ }^{\circ} \mathrm{C}$.

Five hours after the injections, bioimaging of the injected embryos was carried out. Individuals that showed 100-200 cells at the injection area and with no cells observed in blood vessels were selected for future analysis.

\section{Bioimaging}

Bioimaging of the embryos after xenotransplantation was performed using a Leica ICC50 HD direct fluorescence microscope (Leica Microsystems CMS GmbH, Wetzlar, Germany) equipped with a filter for GFP reporter. Evaluation of tumor cell migration in the embryo body was done using the injected embryos' digitized images. The bioimaging of injected embryos was performed 2 days after transplantation. The percentage of the embryos with migration of transplanted cells from the injection site was estimated.

\section{Results}

\section{Construction of PANC-I cell line overexpressing PDXI and PDXI knockdown with anti-PDXI siRNA}

Figure 1A shows the scheme of the lentiviral construct used to analyze the effects of $P D X 1$ overexpression on gene expression in PANC-1 cells. We used the PCNA promoter, a constitutive cellular promoter described by us earlier ${ }^{18}$ for gene expression. This promoter provides some benefits for constitutive expression of transgenes in human cells. The PCNA promoter is highly active compared to other known human promoters in a wide spectrum of normal and tumor cells of human and murine origin. Due to its smaller size, the promoter is convenient for cloning into many genetically engineered vectors sensitive to the size of inserts and allows to use longer transgene inserts.

According to Western blot data (Figure 1B), the expression of PDX1 protein in PANC-1 ${ }^{P D X 1}$ cells was conspicuously higher than in PANC-1 ${ }^{\text {Control }}$ cells. The expression of PDX1 protein in PANC-1 $1^{P D X 1}$ cells treated with siPDX1 was lower than in those treated with siNeg. Real-time PCR data confirmed that the relative level of PDX1 transcript in PANC-1 ${ }^{P D X 1}$ cells 100 -fold exceeded that in PANC-1 ${ }^{\text {Control }}$ cells (data not shown). All the results above confirmed the successful construction of $P D X 1$ overexpression in PANC-1 cells and $P D X 1$ downregulation in PANC-1 ${ }^{P D X 1}$ cells.

\section{PDXI impact on PANC-I cell proliferation} Cell proliferation rates of PANC-1 ${ }^{\text {Control }}$ and PANC-1 ${ }^{\text {PDX1 }}$ cells were analyzed by MTS assay. The results of the MTS assay showed that the growth of PANC-1 ${ }^{\text {Control }}$ optical density of cells in the control group was lower than that of PANC-1 ${ }^{\text {PDX1 }}$ cells $(P<0.05, P<0.01)$ (Figure 2A).

According to the flow cytometry results, the percentage of PANC-1 $1^{\text {Control }}$ and PANC-1 ${ }^{\text {PDX1 }}$ cells in the S stage was $62 \%$ and $45 \%$, respectively. The results revealed that the number of cells in the $\mathrm{S}$ stage of PANC-1 ${ }^{\text {PDX1 }}$ cells was smaller compared with that in the control group, whereas the number of cells in the G1 and G2 stages of PANC$1^{\text {PDX1 }}$ cells was higher than that of PANC-1 ${ }^{\text {Control }}$ cells (Figure 2B).

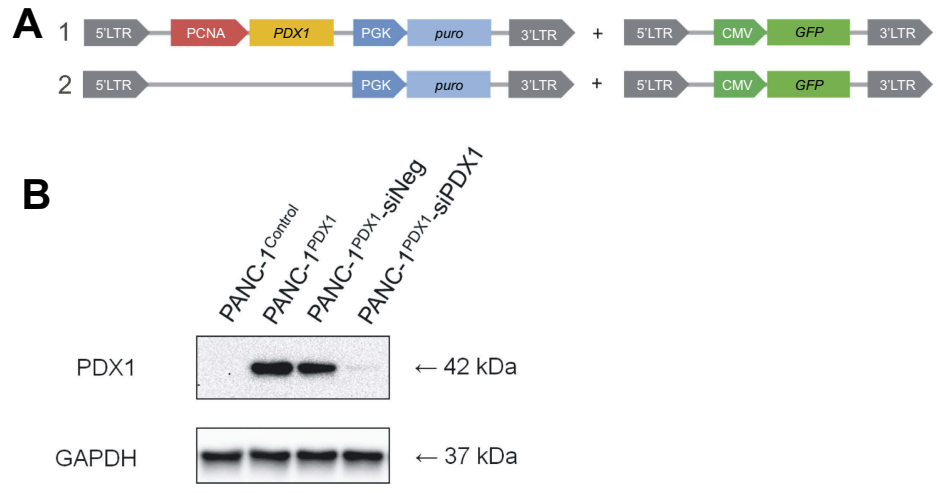

Figure I Construction of PDXI overexpression in PANC-I cells. (A) Scheme of the lentiviral construct used to obtain GFP-labeled PANC-I ${ }^{\text {PDXI }}$ (I) and PANC-I Control (2) cells. (B) Western blot analysis of the expression of the PDXI protein in PANC-I ${ }^{P D X I}$ cells and in the PANC-I ${ }^{\text {Control }}$ group, and the expression of PDXI in PANC-I $I^{P D X I}$ after treatment with anti-PDXI siRNA and negative siRNA. Abbreviations: PCNA - proliferating cell nuclear antigen gene promoter; PDXI -Pancreatic And Duodenal Homeobox I gene; PGK promoter of 3-phosphoglycerate kinase gene; puro - puromycin-resistance gene encoding N-acetyl-transferase; CMV - cytomegalovirus promoter; GFP - green fluorescent protein gene, 5'-LTR, 3'- LTR - 5' and 3' long terminal repeat; GAPDH - Glyceraldehyde 3-phosphate dehydrogenase; kDa - kilodalton. 

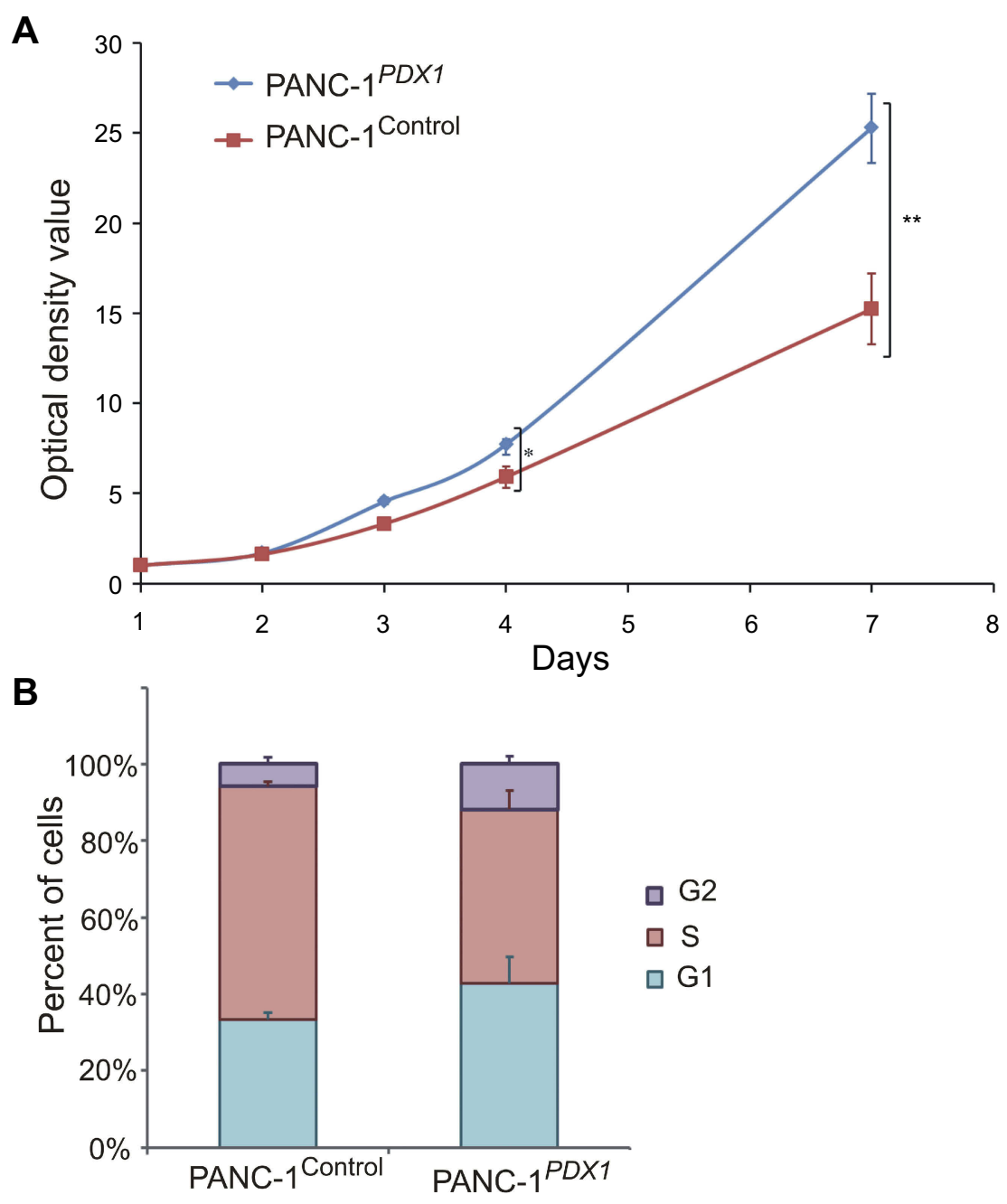

Figure 2 Effects of PDXI overexpression on PANC-I cell proliferation. (A) Growth curves of cells were plotted after transfection with indicated vectors by MTT assays. The OD value of cells in the control group was lower than that of PANC-1 ${ }^{P D X I+}$ cells. $* P<0.05, * * P<0.01$ compared with control group (B) Flow cytometry results showed

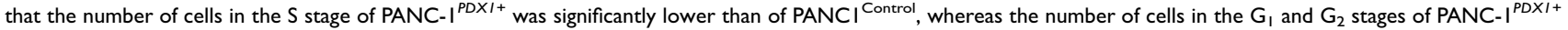
cells was higher than that of PANCI. ${ }^{\text {Control }}$

\section{Suppression of migration and invasion of the PANC-I cells due to overexpression of PDXI}

To test the effect of $P D X 1$ expression on cell motility, a wound healing assay was employed. Compared with PANC-1 ${ }^{\text {Control }}$ cells, wound repair of PANC-1 ${ }^{\text {PDXI }}$ cells was slowed down (Figure 3A). In addition, transwell migration assay results showed that the number of migrated cells expressing $P D X 1$ was smaller than that of the control cells after $24 \mathrm{hrs}$ (Figure 3B). As a whole, the expression of $P D X 1$ significantly reduced both the migration and the invasion of human pancreatic cancer cells.

\section{PDXI expression affects the expression of pro-epithelial and pro-mesenchymal genes}

The expression of the main pro-epithelial and pro-mesenchymal genes in PANC-1 cell line that expresses PDX1 was estimated. The results obtained are presented in Figure 4.

The $M U C 1, K R T 8$, and $C D H 1$ genes whose expression is characteristic of the epithelial cell type and KLF5 that maintains epithelial characteristics of cells were used as pro-epithelial markers. ${ }^{21}$ VIM, which is actively expressed in the mesenchymal cells, and SNAIL, SLUG, and ZEB1, which are transcriptional repressors of E-cadherin transcription and expressed in mesenchymal cell types, were used as pro-mesenchymal markers. 


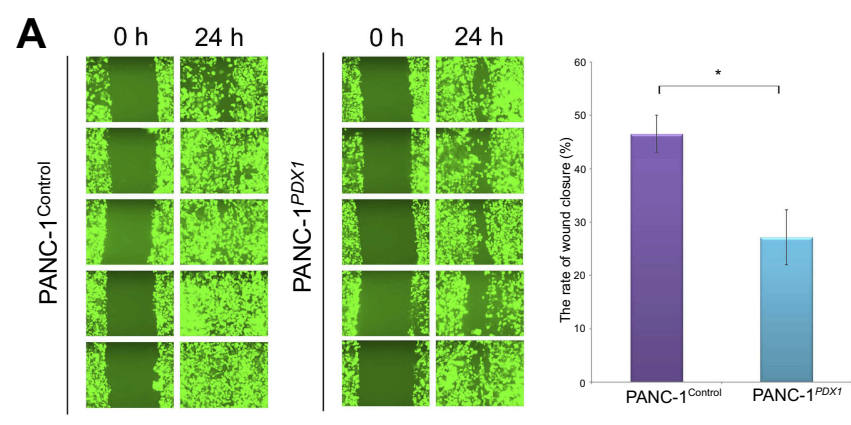

B

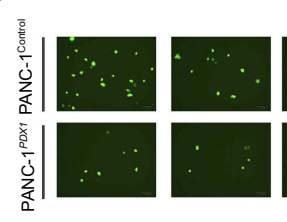

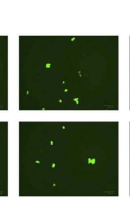
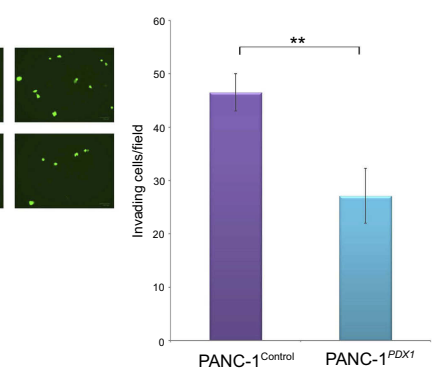

Figure 3 Expression of PDXI significantly reduces both migration and invasion of human pancreatic cancer cells. (A) Effect of PDXI overexpression on pancreatic cancer cell wound recovery. Nearly confluent cell monolayers of PANC-I ${ }^{\text {Control }}$ and PANC- $\left.\right|^{P D X I}$ cells were scratched, and wound recovery was monitored after 24 hrs. The rate of wound closure \pm SEM is shown. The experiment was performed in triplicate with a similar trend. (B) The transwell cell invasion assay of PANC-I Control and PANC-I ${ }^{\text {PDXI }}$ cells. Representative fields of invasive cells on a membrane are captured. The average number of invasive cells per field from three independent experiments \pm SEM is shown. $* P<0.05$; $* * P<0.01$.

It can be seen that the expression levels of epithelial genes, such as $M U C 1, K R T 8$, and $C D H 1$, were slightly increased in PANC-1 ${ }^{P D X 1}$ cells, but the expression level of the mesenchymal transcription factor gene ZEB1 was decreased, although the expression of the mesenchymal genes VIM and SLUG was slightly increased.

\section{Assessment of the migration potential of pancreatic cancer cells expressing PDXI in zebrafish}

Green fluorescent-labeled PANC-1 ${ }^{\text {Control }}$ and PANC-1 ${ }^{P D X 1}$ cells were injected into the yolk sac of zebrafish embryos at $48 \mathrm{hpf}$. In all, over 500 embryos were analyzed in 8 independent experiments. As shown in Table 2, PANC-1 ${ }^{P D X 1}$ cells microinjected into zebrafish embryos at $2 \mathrm{dpt}$ (days post-transplantation) exhibited a lower level (average 12.5\%) of migration as compared with PANC-1 ${ }^{\text {Control }}$ cells (average 50\%). Figure 5 demonstrates representative images of the migration of PANC-1 $1^{P D X 1} /$ PANC-1 ${ }^{\text {Control }}$ cells within the injected embryos.

Further, we examined the effects of knockdown of $P D X 1$ expressed in PANC-1 ${ }^{P D X 1}$ cells. The cells were transfected with siRNA prior to their injection into the yolk sac of the fish. The efficient knockdown of $P D X 1$ in PANC-1 ${ }^{P D X 1}$-siPDX1 was confirmed by Western blot analysis (Figure 1B). The effect of the PDX1 knockdown on PANC-1 $1^{P D X 1}$ cells was then evaluated morphologically in vivo. The $P D X 1$-knockdowned and control cells were injected into the yolk sac of zebrafish embryos at $48 \mathrm{hpf}$. As shown in Table 2, PANC-1 $1^{P D X 1}$-siPDX1 cells microinjected into zebrafish embryos at $2 \mathrm{dpt}$ exhibited considerably higher levels of migration (average 40\%) as compared with PANC-1 $1^{P D X 1}$-siNeg cells (average 6\%).

These findings suggested that, first, zebrafish embryo models could be used to monitor the migration of pancreatic cancer cells in a living animal, and, second, expression of $P D X 1$ caused a significant reduction in pancreatic cancer cell migration in vivo.

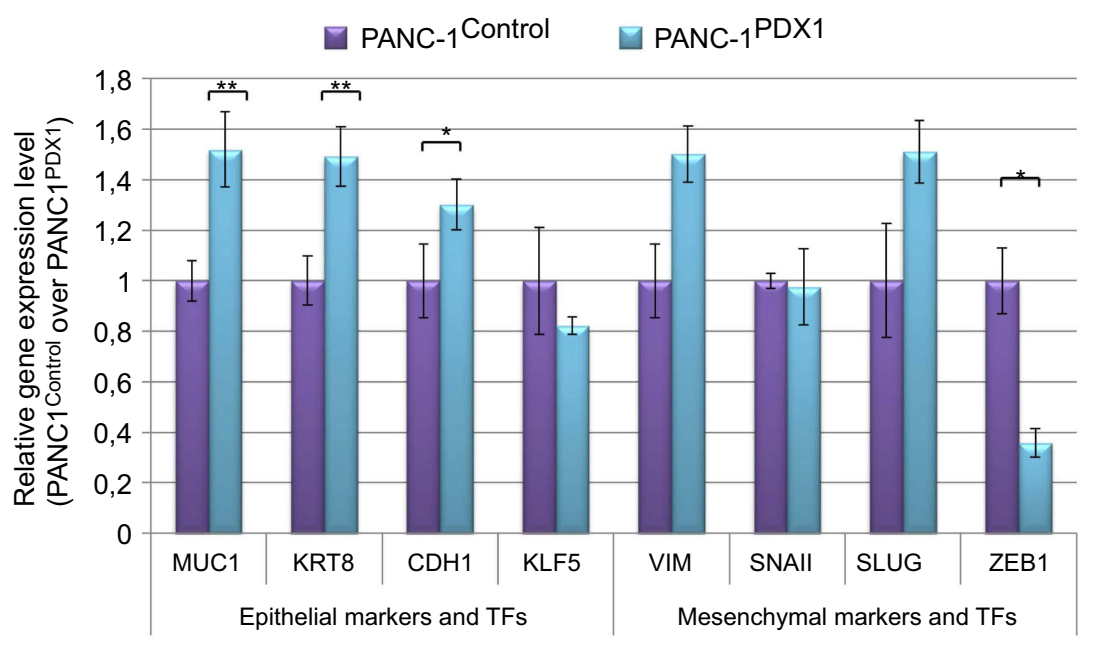

Figure 4 Relative expression of pro-epithelial and pro-mesenchymal genes in PANCI ${ }^{\text {Control }}$ and PANC-I ${ }^{\text {PDXI }}$ cells. TFs are the transcription factors. Data are presented as the mean \pm SEM for three to five independent experiments; $* P<0.05, * * P<0.01$ compared with the control group. 
Table 2 Quantitation of embryos with migrating cells ${ }^{\mathrm{a}}$

\begin{tabular}{|l|l|l|l|l|l|}
\hline Cells & \multicolumn{2}{|l|}{ PANC-I Control } & PANC-I PDXI \\
\hline siRNA & No siRNA & siPDXI & siNeg & No siRNA & siPDXI \\
\hline$\%$ of embryos with migration & $50 \%$ & $30 \%$ & $23 \%$ & $12,5 \%$ & $40 \%$ \\
\hline
\end{tabular}

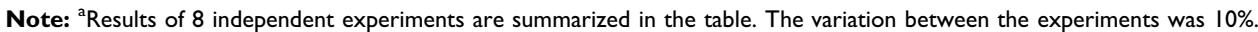
Abbreviation: PDXI, pancreatic and duodenal homeobox I.

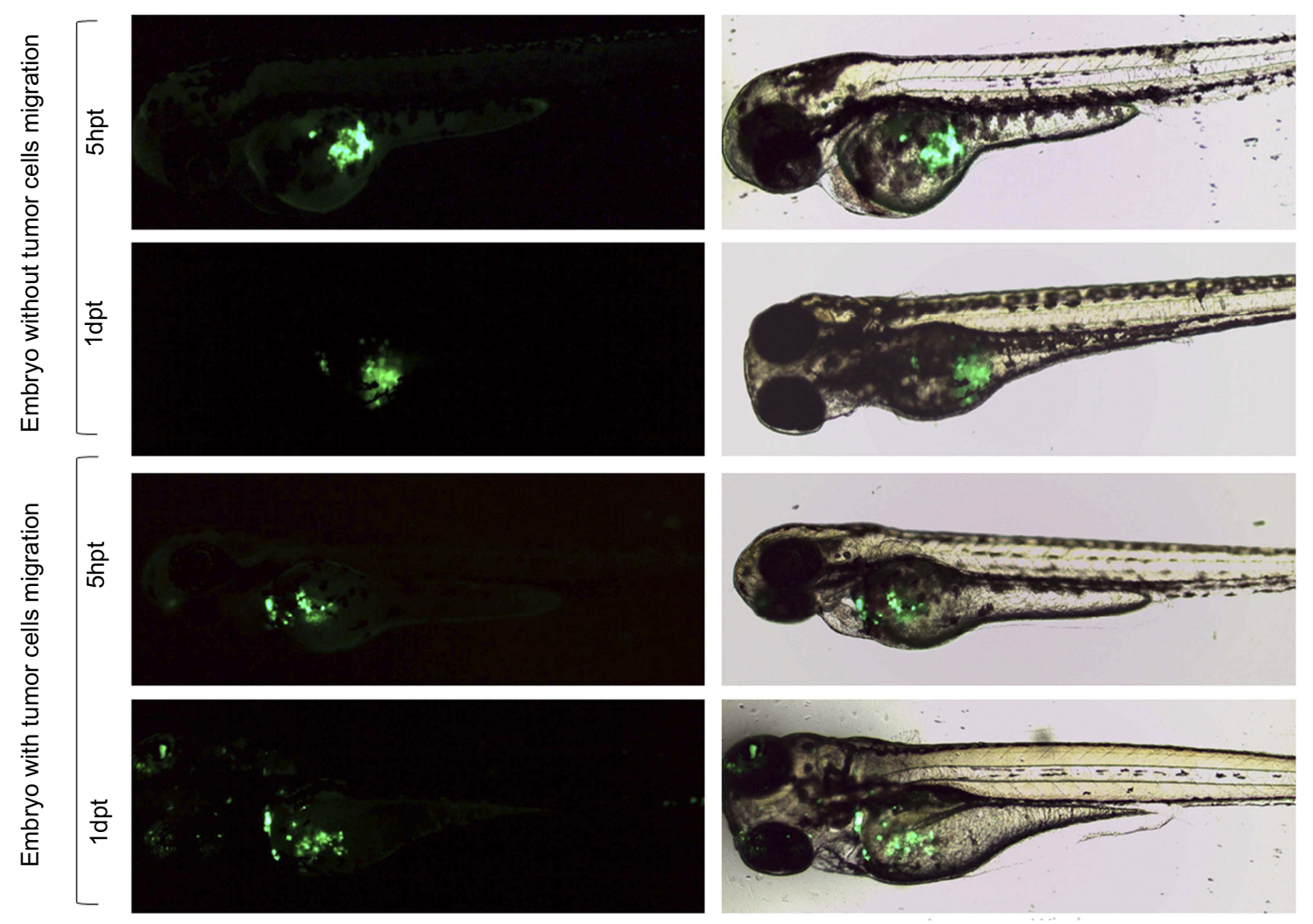

Figure 5 Representative images of migration of PANC-I ${ }^{\text {PDXI} / P A N C-I ~ C o n t r o l ~ c e l l s ~ w i t h i n ~ i n j e c t e d ~ e m b r y o s . ~ F l u o r e s c e n t ~(l e f t) ~ a n d ~ b r i g h t / f l u o r e s c e n t ~ f i e l d s ~(r i g h t) ~ i m a g e s ~ a r e ~}$ presented $20 \times$ magnification. hpt is hour post-transplantation, dpt is days post-transplantation.

\section{Discussion}

Yu et $\mathrm{al}^{16}$ tried to apply Pdx1 to achieve a therapeutic effect by suppressing $P d x l$ expression. However, as pointed out by Roy et al, this was in disagreement with the fact that the most aggressive types of cancer are characterized by the lowest levels of PDX1 and the worst results were in patients whose tumors lacked PDX $1 .{ }^{12}$ This observation raises the question, if gene therapeutic delivery of $P D X 1$ into tumors with low levels of PDX1 could have a therapeutic value and, in particular, if it could not be that PDX1, which, as Roy assumed, was suppressing EMT, is an antimetastatic agent. To check this hypothesis, Danio rerio is an ideal model. It allowed to evaluate the inherent activity of PDX1, separating it from multiple factors of the PDAC microenvironment, although one cannot fully exclude that in the organism of this fish PDX1 still has partner(s) to inhibit the motility of human cells.

The results obtained in our work allow suggesting that PDX1 has indeed potential EMT suppressor activity, which is fully in keeping with the data of Roy et $\mathrm{al}^{12}$ regarding the role of PDX1 as a suppressor of the EMT at the late stages of PDAC development. This activity decreases the motility of cells probably due to inhibiting their epithelial-mesenchymal transition. 
This conclusion is based on three groups of observations.

1. Cell motility in a wound healing assay was slowed down in PANC-1 ${ }^{P D X 1}$ cells as compared to original PANC-1 ${ }^{\text {Control }}$ cells (Figure 3A).

2. Transwell migration assay results showed that the number of migrated cells expressing $P D X 1$ was smaller than that of control cells (Figure 3B).

3. The data of Table 2 demonstrate a significant decrease in the migration rate of PANC-1 ${ }^{P D X 1}$ cells as compared to original PANC-1 cells. This effect is most likely in a causal relationship with the expression of PDX1, since the suppression of this expression with the help of siRNA causes a synchronous increase in cell motility.

The mechanism of this inhibition of cancer cell spread and its relation to metastasis remains to be determined. As mentioned above, the development of metastases may be correlated to a more mesenchymal transcriptomic subtype. ${ }^{10} \mathrm{We}$ evaluated the expression of the main pro-epithelial and promesenchymal genes in PANC-1 cell line that expresses PDX1. The results obtained are presented in Figure 5 concerning pro-mesenchymal genes, expression of VIM and $S L U G$ is slightly enhanced, while that of ZEB1 is markedly decreased. Recently, it has been claimed that EMT is dispensable for metastasis ${ }^{13,14}$ because genetic depletion of the Snail or Twist1 EMT activators had no effect on tumor initiation, invasion, or metastasis in a mouse model of PDAC. Later, Chen et $\mathrm{al}^{22}$ confirmed the existence of EMT-dependent and EMT-independent metastasis in an independent model. However, Krebs et $\mathrm{al}^{23}$ demonstrated that "In contrast to SNAIL and TWIST1, depletion of ZEB1 strongly affected the formation of precursor lesions, tumor grading, invasion and notably metastasis during PDAC progression." The authors concluded "that EMT is important for metastasis, but there is considerable variability and tissue specificity (and not redundancy) in the role and function of different EMT-transcription factors."

Based on the data of Krebs et al, ${ }^{23}$ we suppose that in our case a ZEB1-dependent EMT program is being carried out. A significantly reduced level of $Z E B 1$ expression, together with the almost unchanged expression of SNAIL and SLUG may lead to a diminished EMT ability of PANC-1 cells and their reduced motility and metastatic activity.

On the other hand, factors maintaining the epithelial character of cells act in the same direction. The content of these factors (eg, PDX1: KRT8, MUC1, and CDH1) in cells expressing PDX1 is increased, although the content of KLF5 is not changed.

\section{Conclusion}

In conclusion, we believe that our data confirmed the PDX1 role as an EMT suppressor and thus, possibly, metastasis inhibitor. Further experiments on a more close-to-human model, such as a mouse, will allow to investigate this problem in more detail and to evaluate the possibility of using PDX1 as an antimetastatic agent in medicine.

\section{Acknowledgments}

The authors are thankful to Dr. B.O. Glotov for his help in preparing the paper and to Dr. K.N. Kashkin for siRNA design. The study was supported by the Russian Science Foundation (project no. 19-15-00317). The Danio rerio model development was supported by the Russian Foundation of Basic Research (project no.17-00-00194 $(\mathrm{K})$ ). In vivo experiments were carried out on the equipment of the Center for Collective Use of the Institute of Molecular Genetics of the Russian Academy of Sciences.

\section{Disclosure}

The authors report no conflicts of interest in this work.

\section{References}

1. Dugnani E, Sordi V, Pellegrini S, et al. Gene expression analysis of embryonic pancreas development master regulators and terminal cell fate markers in resected pancreatic cancer: A correlation with clinical outcome. Pancreatology. 2018;18:945-953. doi:10.1016/j. pan.2018.09.006

2. Ansari D, Friess H, Bauden M, Samnegard J, Andersson R. Pancreatic cancer: disease dynamics, tumor biology and the role of the microenvironment. Oncotarget. 2018;9(5):6644-6651. doi:10.18632/ oncotarget.24019

3. Reichert M, Blume K, Kleger A, Hartmann D, von Figura G. Developmental pathways direct pancreatic cancer initiation from its cellular origin. Stem Cells Int. 2016;2016:1-8. doi:10.1155/2016/ 9298535

4. Fischer CG, Wood LD. From somatic mutation to early detection: insights from molecular characterization of pancreatic cancer precursor lesions. J Pathol. 2018;246(4):395-404 doi:10.1002/path.5154

5. Mostafa ME, Erbarut-Seven I, Pehlivanoglu B, Adsay V. Pathologic classification of "pancreatic cancers": current concepts and challenges. Chin Clin Oncol. 2017;6(6):59. doi:10.21037/cco.2017.12.01

6. Ren B, Cui M, Yang G, et al. Tumor microenvironment participates in metastasis of pancreatic cancer. Mol Cancer. 2018;17(1):108. doi:10.1186/s12943-018-0858-1

7. Chitty JL, Filipe EC, Lucas MC, Herrmann D, Cox TR, Timpson P. Recent advances in understanding the complexities of metastasis. F1000Res. 2018;7:1169. doi:10.12688/f1000research.15064.2 
8. Wang S, Huang S, Sun YL. Epithelial-mesenchymal transition in pancreatic cancer: a review. Biomed Res Int. 2017;2017:1-10. doi: $10.1155 / 2017 / 2646148$

9. Giovannetti E, van der Borden CL, Frampton AE, Ali A, Firuzi O, Peters GJ. Never let it go: stopping key mechanisms underlying metastasis to fight pancreatic cancer. Semin Cancer Biol. 2017;44:43-59. doi:10.1016/j.semcancer.2017.04.006

10. Le Large TYS, Bijlsma MF, Kazemier G, van Laarhoven HWM, Giovannetti E, Jimenez CR. Key biological processes driving metastatic spread of pancreatic cancer as identified by multi-omics studies. Semin Cancer Biol. 2017;44:153-169. doi:10.1016/j.semcancer.2017.03.008

11. Sverdlov E. Missed druggable cancer hallmark: cancer-stroma symbiotic crosstalk as paradigm and hypothesis for cancer therapy. Bioessays. 2018;40(11):1800079. doi:10.1002/bies.201800079

12. Roy N, Takeuchi KK, Ruggeri JM, et al. PDX1 dynamically regulates pancreatic ductal adenocarcinoma initiation and maintenance. Genes Dev. 2016;30(24):2669-2683. doi:10.1101/gad.291021.116

13. Fischer KR, Durrans A, Lee S, et al. Epithelial-to-mesenchymal transition is not required for lung metastasis but contributes to chemoresistance. Nature. 2015;527(7579):472-476. doi:10.1038/nature15748

14. Zheng X, Carstens JL, Kim J, et al. Epithelial-to-mesenchymal transition is dispensable for metastasis but induces chemoresistance in pancreatic cancer. Nature. 2015;527(7579):525-530. doi:10.1038/nature16064

15. Borazanci E, Dang CV, Robey RW, Bates SE, Chabot JA, Von Hoff DD. Pancreatic cancer: "a riddle wrapped in a mystery inside an enigma”. Clin Cancer Res. 2017;23(7):1629-1637. doi:10.1158/ 1078-0432.CCR-16-2070

16. Yu J, Liu SH, Sanchez R, Nemunaitis J, Rozengurt E, Brunicardi FC. PDX1 associated therapy in translational medicine. Ann Transl Med. 2016;4(11):214. doi:10.21037/atm.2016.03.51
17. Kashkin KN, Chernov IP, Didych DA, Sverdlov ED. Construction of a combinatorial library of chimeric tumor-specific promoters. BioTechniques. 2017;63(3). doi:10.2144/000114586

18. Kondratyeva LG, Kashkin KN, Chernov IP, et al. PCNA: a constitutive human promoter for gene expression for functional studies and therapeutic applications. Mol Genet Microbiol Virol. 2018;32(3):137140. doi:10.3103/S089141681703003X

19. Kondratyeva LG, Didych DA, Chernov IP, et al. Dependence of expression of regulatory master genes of embryonic development in pancreatic cancer cells on the intracellular concentration of the master regulator PDX1. Doklady Biochem Biophys. 2017;475(1):259263. doi:10.1134/S1607672917040056

20. Ganger MT, Dietz GD, Ewing SJ. A common base method for analysis of qPCR data and the application of simple blocking in qPCR experiments. BMC Bioinformatics. 2017;18(1). doi:10.1186/ s12859-017-1949-5

21. Abjalimov IR, Zinovyeva MV, Nikolaev LG, Kopantzeva MR, Kopantzev EP, Sverdlov ED. Expression of transcription factor genes in cell lines corresponding to different stages of pancreatic cancer progression. Doklady Biochem Biophys. 2017;475(1):267270. doi:10.1134/S160767291704007X

22. Chen Y, LeBleu VS, Carstens JL, et al. Dual reporter genetic mouse models of pancreatic cancer identify an epithelial-to-mesenchymal transition-independent metastasis program. EMBO Mol Med. 2018;10 (10):e9085. doi:10.15252/emmm.201809085

23. Krebs AM, Mitschke J, Lasierra Losada M, et al. The EMT-activator Zeb1 is a key factor for cell plasticity and promotes metastasis in pancreatic cancer. Nat Cell Biol. 2017;19(5):518-529. doi:10.1038/ ncb3513

\section{Publish your work in this journal}

Cancer Management and Research is an international, peer-reviewed open access journal focusing on cancer research and the optimal use of preventative and integrated treatment interventions to achieve improved outcomes, enhanced survival and quality of life for the cancer patient
The manuscript management system is completely online and includes a very quick and fair peer-review system, which is all easy to use. Visit http://www.dovepress.com/testimonials.php to read real quotes from published authors. 